Ana Helfant

\title{
El paisaje $y$ el. hombre en la pintura chilena (1)
}

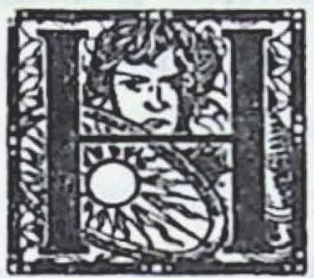

ABLAR de pintura chilena ante un público chileno es tema harto difícil. Cada uno de los que me escuchan tienen, sin duda, algunos conocimientos de pintores. Al pasar por alto el nombre de éste o de aquél, podría parecer un lamentable olvido. Sin embargo, debemos admitir que en el breve espacio de una charla, no podemos abarcar a todos nuestros pintores. También debo añadir que en calidad de crítico de arte, debo ser fría e imparcial en mis juicios, sin permitirme el lujo de tener simpatías o antipatías personales por éste o aquél otro artista.

Se preguntarán ustedes entonces cómo voy a seleccionar los artistas de los cuales voy a tratar esta tarde.

Cuando hace algún tiempo atrás tuve la oportunidad de salir al extranjero con la misión de la Universidad de Chile para divulgar la plástica chilena, se me planteó el mismo problema. Me di cuenta entonces que había llegado el momento para nosotros de encarar la historia de la pintura chilena desde un ángulo distinto. En vez de la compilación de datos y de nombres, cada vez más abundante, se hace necesaria la selección y el juicio crítico frente al total de lo

(1) Conferencia dictada en el Salón de Honor de la Universidad de Concepción el día 10 de agosto de 1956. 
conocido. Por ese error de no clasificar, de incluir democráticamente a todos nuestros artistas sobre un mismo nivel, nos hemos presentado mal en certámenes internacionales. $Y$ eso no puede seguir. Como en todas partes, tenemos buenos y malos pintores. Si mezclamos los buenos con los malos, el resultado es que el conjunto desmerecerá. Cuando se trata de juzgar un conjunto, hay que estar alerta.

Hemos llegado, pues, a la hora en que se impone una revisión de nuestros valores plásticos, una revisión en donde los sentimentalismos sean ajenos al aprecio de la obra de arte en sí. En vez de presentar una enciclopedia de nombres, mencionaremos unos cuantos, los mejores, los más destacados. Hagamos lo que el jardinero que quiere obtener un bonito ejemplar de rosa, y poda el arbusto. Pero si hablamos de jardinero, cuidado al podar, no cortemos también el ejemplar de la flor que deseamos hacer lucir. Al referirme a esta actitud, pienso en aquellos que niegan la existencia de una pintura nacional.

El chileno es un ser modesto, y esto es una gran cualidad para un pueblo y para un país. Es precisamente esta modestia, esta insatisfacción por las cosas ya realizadas, esa inquietud por alcanzar mayor nivel en todo orden, lo que está produciendo el progreso del país. Al contrario de otros países siempre satisfechos de sí mismos, Chile ha progresado y está tomando la delantera bajo muchos aspactos en el continente, gracias a esta insatisfacción y ese afán de superación.

Pero si la modestia es una cualidad muy fructífera, no debemos caer - en nombre de esa misma modestia- en una actitud negativa frente a nuestros valores. Es ya del dominio público que Chile está consiguiendo un nivel cultural superior al alcanzado por la mayoría de los países de Latinoamérica. Nuestras Universidades están pasando a la cabeza de sus congéneres de habla castellana y cientos y miles de estudiantes de este continente vienen a buscar enseñanza en ellas. Nuestros poetas se están colocando en la primera fila de la poesía de habla castellana, y nuestros músicos pasean triunfalmente por el extranjero el nombre de Chile. 
¿Y nuestra pintura entonces? ¿Hemos quedado a la zaga en materias de artes plásticas?

$\mathrm{El}$ arte no es ni una moda ni una novedad. Por eso no se puede exigir pintar de ésta o aquélla manera. Si hoy trataremos de los artistas que desde el impresionismo hasta nuestros días han estado en la línea de la pintura moderna, es porque considero que el arte es una expresión, y como tal debe estar de acuerdo con el lenguaje de su época. En Chile, a la hora del impresionismo, hemos tenido impresionistas, y a la hora del arte moderno, tenemos un arte moderno. Debemos estar alerta y preocuparnos de aquellos artistas que sintieron y vibraron con la inquietud del momento. Ellos expresan lo que otros sienten y callan.

Otro reproche que se ha venido haciendo a la pintura chilena es su carencia de una "modalidad" nacional. Esto ha hecho desarrollar en el campo contrario un grupo de artistas nacionalistas. Magnífica idea, pero cuyos frutos fueron un tanto estériles. No se hace labor de chilenidad porque se pintan huasos. En materia artística, es siempre peligroso llevar forzosamente de la mano a la gente y darle órdenes de pensar o de sentir de determinada manera. El arte debe convencer por la sugerencia, por una invitación a la meditación, pero jamás puede ser una orden perentoria para pensar en cierta forma. Cuando Velázquez, Zurbarán o Goya pintaron, no pensaron entonces que definirían los caracteres de la escuela española. Pintaron simplemente lo que vieron y sintieron, y con ello marcaron ángulos definitivos de su país.

Luego pongámonos en guardia ante las definiciones fáciles, so pena de caer en lo superficial y lo barato. Ortega y Gasset dice: "Hay que aprender a libertarse de la sugestión tradicional que hace consistir siempre la realidad en alguna "cosa", sea corporal, sea "mental". Y añade después: "No hay un vivir abstracto. Vida significa la inexorable forzosidad de realizar el proyecto de existencia que cada cual es..." Pero Ortega en esta ocasión se muestra existencialista. Busca la existencia del ser por dentro del ser, y no por fuera de él. Hagamos lo mismo con los países, porque como dijo el pen- 
sador español: "No hay un vivir abstracto". Y eso implica inmediatamente: "la inexorable forzosidad de realizar el proyecto de existencia..."

Para una nación, ese proyecto empieza a realizarse desde su marcación geográfica, que es ya como un destino ineludible. $\mathrm{Y}$ sin embargo, admitimos con toda naturalidad esa posición continental. ¿Se ha preguntado alguien si Chile sería el mismo país, sin esta loca geografía que corre a través de treinta y ocho paralelos? Evidentemente no es fácil imaginarlo, pero podemos pensar que tal vez no hubiera existido ni Caupolicán, ni O’Higgins, ni Portales. Desde el momento de tener otra posición geográfica todo cambiaría. La vegetación, la historia, etc.

Cuando empezamos a darnos cuenta que un país está en función de su posición geográfica, empezamos a tener ya una idea cabal no de una nación cualquiera, que lo mismo da que esté en el Ecuador que en alguno de los polos, sino de una existencia propia, que respira a cierta altura y se conmueve en determinados casos. Luego empezamos a comprender que ese país tiene una existencia propia, individual, que aunque sea parecida a otras, nunca será idéntica.

Por lo tanto, aunque admitamos la influencia del arte europeo en la plástica nacional, no tenemos derecho a dudar por ello de la existencia de una pintura chilena. Hay algo profundo, algo que nace no del intelecto sino del subconsciente que ata al hombre a la tierra. Gabriela Mistral dice: - "Me gusta la idolatría de la tierra, que está en todos los folklores, y no sólo porque la entiendo, sino que la vivo a plena anchùra. La tierra fué siempre el Gran Idolo, como que ella es la bandeja en que se asientan todas las demás adoraciones humanas".

Al mirar nuestro mapa, ¿se han detenido ustedes a pensar en el significado de nuestras fronteras naturales? Por un lado el Océano. Es muy simple decir el Océano. Pero cuando a esa noción de horizonte azul añadimos la pavorosa cifra de cuatro mil doscientos kilómetros de costa, ese Océano deja de ser un mar cualquiera y pasa a ser una constante mal llamada Pacífico. La corriente polar de 
Humboldt enfría nuestra costa, y este mar, embriagado de anchura no nos conduce - en línea recta - a ninguna parte. Mientras algunos pueblos como Noruega o Grecia o Inglaterra miran el mar por delante, en Chile lo consideramos - hasta la fecha- a nuestras espaldas.

Volvamos la cabeza en dirección contraria. La inmensa mole de la cordillera se yergue frente a nosotros. La gran, la terrible cordillera, la que arroja orgullosa contra el cielo sus picachos de nieves eternas, la de granito, la que muestra descarnadamente al viajero sus vetas multicolores, la que embruja al minero con la riqueza de su seno. Ese hechizo de la cordillera andina, la despoblada, la árida, que mal soporta sobre su lomo el árbol, amigo del hombre. La cordillera está en todas partes, nuevamente la cordillera, siempre la cordillera, ora envuelta en grises de bruma, ora palpable de blancos y azules, o malva y rosa al atardecer, o azul al amanecer.

La naturaleza, siempre la naturaleza, rica, generosa, aplastante. El hombre desaparece frente a ella. Su ser queda en éxtasis ante esta belleza pagana que se ofrece a sus ojos, siempre erguida en el horizonte, dándole todo, pero dominándolo, recordándole la diferencia de proporciones. Por eso gran parte de nuestra pintura está impregnada de paisaje. Por eso el pintor chileno vuelve una y otra vez al asalto de esta naturaleza que trata de dominar, de poseer.

Desde los románticos paisajes de Antonio Smith a mediados del siglo pasado hasta los abstractos de Vargas Rosas o de algunos jóvenes de las generaciones más nuevas; ¡cuántos cambios estéticos! Pero siempre una constante: el paisaje, la naturaleza, pedazos del campo o trozos de playas, flores y frutas, todo esto reflejo de esta tierra, reflejo de la naturaleza.

Durante un buen tiempo, el hombre no creaba problemas. Vivía tranquilo en su rancho, en su fundo, en su ciudad o viajaba a Europa. Y durante mucho tiempo también, el hombre sólo ha tenido ojos para mirar este magnífico espectáculo que la naturaleza le brindaba, este paisaje hecho de luz, de sol, de brumas transparentes que 
difumina los rasgos duros de la montaña y tal vez impregna de cierta dulzura también el carácter.

La influencia europea trae a Chile a varios pintores extranjeros. El alemán Juan Mauricio Rugendas, luego el angloamericano Wood, el francés Charton y sobre todo su compatriota Monvoisin, el más importante tal vez de todos los visitantes pintores de aquellos tiempos en Chile. Somerscales llega más tarde. Todos estos pintores dejan una estela de su paso. Pero son estelas trazadas en la arena, no perduran largo tiempo.

La Academia de Bellas Artes, fundada en 1849 vino a llenar el anhelo que se sentía, de crear un ambiente artístico. Los primeros directores de esta Academia, Cicarelli, Kirbach y Mochi fueron solemnes pintores académicos. ¿Qué es lo que ellos comprenden de Chile? Nada. Pero en el país existe una inquietud artística fuerte, por esa misma época.

Pero Lira es el primer resultado importante de este movimiento. Discípulo de Ciccarelli, Pedro Lira tuvo la personalidad suficiente para buscar y hallar otros maestros, otras enseñanzas. Fué no sólo un pintor sino también un animador de las artes. Pero Lira, al igual que Valenzuela Puelma, concibe una pintura de taller. Sin embargo, a fines del siglo pasado se produce una corriente opositora a esta-pintura objetivista. El temperamento del pintor chileno, más intuitivo que reflexivo no soportó por más tiempo la rígida disciplina académica. Al paisaje de taller o frente a la figura de la modelo, el artista nacional preferirá salir a pintar la montaña o los árboles en flor, en fin de cuentas esa naturaleza que le rodea y obsesiona. El estilo del plein air encajará perfectamente en esos artistas que quieren pintar con los pulmones y no sólo con la vista.

¿Influencia europea? Posiblemente. Pero más que nada necesidad de expresar una emoción cercana y constante. Pedro Lira podía conmover a algunos entendidos y eruditos con su Sísifo, y Valenzuela Puelma habrá logrado estremecer a más de una persona con su Perla del mercader. Pero cuando Valenzuela Llanos pinta su Almendros en flor y Juan Francisco González embadurna alguna de sus 
manchas tan celebradas, comprendemos que se han acercado a una verdad nacional, que están tratando de reflejar ese ambiente que respiran a plena anchura.

Aunque Juan Francisco González negará en vida ser un pintor impresionista, si hemos de encajarlo en escuela determinada, es sin duda entre los impresionistas en donde mejor se acopla. Juan Francisco es uno de los pintores nacionales de temperamento más arrebatado. Hay en él un deleite dionisíaco por la naturaleza, el color, la materia. Su obra no refleja patetismo ni sufrimiento. Pinta espontáneamente, a veces hasta tres telas diariamente. De ahí la abundancia de sus cuadros, manchas, bocetos que todavía parece imposible catalogar. Hay quien hace la cuenta que Juan Francisco González vivió ochenta años y empezó a pintar a edad muy temprana. Como el pintar unas tres telas cada día era cosa bastante frecuente en él... tal vez algún matemático sabrá exactamente cuantas obras ha producido.

Lo que él ve son trozos de naturaleza, unas cuantas flores que resplandecen al sol. Generalmente no hay jarro que las sujete ni tallos que las amarren al suelo. Flores y paisajes, simplemente. La lógica que ata los objetos al mundo real y en cierto modo explican su existencia no es cosa que preocupe a Juan Francisco. Su credo estético es la naturaleza que brota, que irrumpe en todas partes y se vuelca en sus telas. Profesor de croquis de la Escuela de Bellas Artes, sus alumnos fueron muchos. A todos alentaba a seguir sus propias tendencias. Al contrario de Pedro Lira que trataba siempre de imponer su criterio, Juan Francisco González respetó la personalidad de sus discípulos. Alfonso Vila es uno de los pintores que todavía sigue en cierto modo la tendencia del maestro. Sin embargo, es un pintor mucho más joven, que no asistió al curso de Juan Francisco, el que mejor continúa la tendencia. Es Carlos Pedraza. Sin embargo, hemos de notar que Pedraza es menos arrebatado para manchar. Su obra se asienta sobre la libertad y sutileza del pincel, que imprime de cierto aire poético sus cuadros.

Pablo Burchard y Agustín Abarca fueron discípulos de Valen- 
zuela Llanos, aunque Burchard, por ser algo mayor de edad, también fué profesor de su amigo Abarca. Ambos pintores tuvieron un encuentro casual en la ciudad de Talca, mientras Burchard se encontraba pintando en un potrero. El destino gusta encender ciertas chispas, y este encuentro hizo encender en Abarca el deseo de pintar. Amigos, pasaron juntos momentos difíciles. Pero uno y otro lograron imponerse al final. Pablo Burchard obteniendo hace algunos años atrás el Premio Nacional de Arte. Abarca de manera muy distinta. $\mathrm{Y}$ es que sus pinturas son distintas también. En Burchard encontramos ciertas preocupaciones de composición, una composición arquitectónica a veces. Sus paisajes son paisajes urbanos, y cuando no, la presencia del hombre parece siempre cercana. Burchard siente cierta inclinación por tratar en sus telas grandes extensiones de pared, de muros. Eso le permite ricos empastes en los tonos claros, una de las características de este pintor. El goce de la materia calcárea le permite una matización cromática de ocres y grises.

Mientras el paisaje de Burchard es poblado, el de Abarca es de soledad. Los extensos bosques del sur, algunos atardeceres en el mar. Abarca no es la desolación, pero sí la soledad. Rebelde a los clanes, se mantuvo por mucho tiempo en un aislamiento voluntario y desdeñoso. Apenas alguna vez que otra enviaba una tela a una exposición. Hace unos años atrás - hacia 1950-, la Sociedad Nacional de Bellas Artes organizó una exposición retrospectiva, y entonces Abarca fué "redescubierto" por muchos aficionados al arte. El había sentido siempre cierto desdén por la crítica y el público. De vez en cuando "se dignaba" (y esa es la expresión exacta) a enviar alguna tela. Cuando así lo hacía, trataba de escoger lo que menos le agradaba. Semejante actitud hizo escribir a Richon-Brunet: "Es difícil encontrar otro ejemplo más completo de pudor intelectual que el del señor Abarca". Y he ahí precisamente un punto muy especial de este caso: el pudor intelectual. Su pintura es un complejo de arte intelectual y de romanticismo que aleja de toda frialdad a lo que está producido por el cerebro. Siempre me siento inclinada a situar a Abarca como a uno de los primeros pintores modernos en Chile, no 
tanto por su tendencia abstracta que caracteriza a la pintura actual, sino por la reacción contra la pintura desenfrenada, la pura pintura de instinto que representó el impresionismo.

El tiempo dirá con mayor claridad, cuál fué el verdadero papel que la obra de Abarca ha de jugar en la pintura nacional. Por mi parte, le atribuyo un lugar primordial. Como Juan Francisco González negaba su impresionismo, Abarca negaba su "modernismo". Formaba parte de la Sociedad Nacional de Bellas Artes en donde le parecía encontrarse más cerca de su concepto pictórico. Aunque alguna vez expuso en el Salón Oficial, su simpatía se inclinaba más hacia el otro lado. Pero, ironía del destino. Si analizamos el panorama de nuestra pintura y buscamos la línea ascendente del arte moderno, nos encontramos a Agustín Abarca como una piedra angular. Personalmente considero que existen tres etapas bien definidas. La primera marcada por Juan Francisco González, al romper los moldes del academismo. La segunda, es la etapa de Abarca, que lleva la pintura hacia un estado analítico de la realidad, la tercera etapa marcada por Vargas Rosas, que llega a la abstracción pura.

Se suele llamar la Generación del Centenario a los pintores que pintaban hacia 1910 y participaron en el gran Salón Oficial de Bellas Artes con motivo del centenario de la República. Son ellos en realidad alumnos del pintor español Alvarez de Sotomayor, por lo que Romera los ha llamado la generación del 13. Debemos reconocer que esta generación se ha perdido en gran parte. Agustín Abarca, que también participó de ella por breve espacio de tiempo, se apartó luego. En modo alguno se le podría juntar al resto del grupo.

La lista completa de esta generación es bastante larga, comprende unos veintitantos, entre los cuales podríamos destacar a Pedro Luna, una de los talentos más sólidos de aquella generación, a Exequiel Plaza y Enrique Bertrix, que murió muy joven en los campos de batalla de Francia.

Los muchachos de entonces eran bohemios, sentimentales, románticos. Gustaban de pintar la luz de la luna, o un parque en sombrío atardecer. Emplear un tono más violento, más vibrante, parecía 
una blasfemia por aquel entonces, como una risa en un cementerio. De todo el grupo, Luna comprendió mejor que nadie la importancia del color. Tal vez hay cierta responsabilidad de Alvarez Sotomayor en tantos pintores extraviados. La ideología del maestro español se impregnó tanto en todos sus discípulos, que ninguno la pudo abandonar del todo. La generación del centenario representa todavía una interrogante dentro de nuestra pintura, y espera el tiempo para resolverse.

Ideológicamente, el siglo XIX se termina hacia el año 20, cuando Chile empieza a perfilar su nueva modalidad. La llamada generación del año 20, fué una generación inflamada de ideales, romántica y luchadora a la vez. Fué la que surtió a la nación de los hombres que rigieron su destino y abarcan todas las actividades. En ella encontramos políticos destacados, senadores, como Santiago Labarca e Isauro Torres, poetas como Roberto Meza Fuentes, Pablo Neruda, escritores como Manuel Rojas y González Vera, pintores como Camilo Mori y Vargas Rosas.

Fué la Universidad de Chile el foco en donde tomó cuerpo este movimiento, viniendo a incorporarse algunos nombres de afuera. Fué por lo tanto un grupo de intelectuales y estudiantes los que formaron las huestes de la FECH (Federación de Estudiantes de Chile) los que por primera vez en la historia del país fueron en su mayoría de la clase media. Las luchas habidas en Chile anteriores a esa época fueron más bien de preocupación republicana. Las del año 20 tuvieron un carácter más social. Para darnos mejor cuenta de lo que eran aquellos universitarios, escuchemos mejor el testimonio de González Vera, quien dice en su libro Cuando era muchacho: "Entre los universitarios había radicales, masones, anarquistas, católicos, socialistas, románticos puros y muchachos casi en estado silvestre".

Me parece que no se puede mencionar la generación del año 20, sin referirse a don Arturo Alessandri, hombre ya en plena madurez por aquel entonces, que encarnó con banda presidencial los ideales de los universitarios. Volveré a recurrir a la autorizada voz de José Santos González Vera, que sabe mirar los acontecimientos sin pasio- 
nes. Dice: “... don Arturo Alessandri, hombre de voz cálida, hecha de templado metal, que podía hablar tres o cuatro horas seguidas, cuya gesticulación era tan elocuente como sus palabras, de un poder de simpatía no superado por ningún otro chileno: vehementísimo, especie de mago que transformaba las frases comunes y las ideas más atrozmente manidas en oro puro. Si uno incurría en la debilidad de escucharle, perdía todas las defensas, y era inevitable que aplaudiera con locura..."

Las leyes sociales que empiezan a ventilarse desde aquel momento demuestran que el hombre ya ha dejado de ser un punto en el paisaje. Los pintores del año 20 empezaron a remecer los viejos conceptos del arte. El año 24 el grupo Montparnasse se organizó con Luis Vargas Rosas, Henriette Petit, José Perotti y Julio Ortiz de Zárate. Luego se añadieron al grupo Camilo Mori, Isaías Cabezón, Romano Dominicis, etc. El grupo Montparnasse introdujo en Chile las corrientes del arte moderno. Desde las páginas de "La Nación", el pintor Alvaro Yáñez, con el pseudónimo de Jean Emar, apoyó el movimiento.

El grupo Montparnasse no tuvo larga vida, pero había sembrado nuevas preocupaciones en arte. En 1928, bajo la primera Presidencia de don Carlos Ibáñez del Campo, se dictó la reforma de la educación y con ella de las artes plásticas. Las primeras disposiciones para realizar esta reforma consistió en un decreto que dispuso el cierre temporal de la Escuela de Bellas Artes. Sólo quedaron funcionando en la misma los cursos de pedagogía del dibujo, para las escuelas primarias y secundarias. El principal motivo de este hecho era el de enviar a las fuentes mismas de la cultura artística, o sea a Europa, un grupo de profesores y alumnos destacados, para perfeccionarse en el método de la enseñanza del arte. Camilo Mori, Gustavo Carrasco, Jorge Caballero, Inés Puyó, Augusto Eguiluz, Ana Cortés, Laureano Guevara, Roberto Humeres, son algunos de los nombres.

Llegamos a preguntarnos: ¿qué trajeron estos pintores de su viaje a Europa, en donde estuvieron en contacto directo con buenos profesores (André Lhote, por ejemplo)? Las tendencias que trajeron 
fueron muy diversas, pero podríamos calificarlas de centradas. Una pintura cubista estilo Picasso o abstracta estilo Kandinsky, hubiera resultado probablemente una transición demasiado brusca. $\mathrm{El}$ impresionismo había penetrado en Chile casi a fines del siglo pasado, cuando se pintaba impresionista en Europa también. Pero la generación del año 10 no siguió la ola renovadora. Fué tarea de los becados del año 29 hacer la transición que el grupo Montparnasse había iniciado.

Considero a Camilo Mori uno de los pintores más difíciles de estudiar de la pintura chilena. Su obra tiene una evolución zigzagueante. Premio Nacional de Arte, las telas de Mori abarcan muchos estilos, desde el cubismo moderado hasta sus retratos envueltos en un halo de romanticismo. Mori pone a un comentarista de arte en cierto aprieto, pues debido a una pequeña deformación profesional tal vez, el comentarista tiene tendencia a ponerle definiciones a todo. En el fondo el comentarista no es más que una especie de policía o gendarme del arte, que desea fichas y casilleros para todo. Y Camilo Mori escapa a todo orden. Hay en él un afán de hacerlo todo, de poseerlo todo, en la medida que toda creación de arte es una posesión del mundo.

Sin embargo, según mi criterio personal me inclino a situar a Luis Vargas Rosas como al primer pintor auténticamente moderno en el país. De carácter retraído, habiendo vivido muchos años en Francia, Vargas Rosas es el actual director del Museo de Bellas Artes. Ha expuesto en París en el Salon des Surindependants, con el grupo de Abstracción-Creación y con los discípulos de Bill Hayter.

Es su preocupación más constante no sólo el ritmo que imprime a su pintura un sentido musical, sino también el movimiento perpetuo. Observaremos en las telas producidas en la madurez esa movilidad que hará hablar a algunos del futurismo de Vargas Rosas. Por mi parte, no me parece ése el espíritu de la obra, pues mientras el futurismo busca el movimiento simultáneo, Vargas Rosas sólo busca la instantánea del movimiento que imprime en sus telas a través del ritmo predominante. Observando por ejemplo los árboles o 
los demás elementos estables y sólidos, los veremos en actitud "andante". Por lo tanto no hay simultaneidad. Así lo podemos observar en sus obras tituladas: Ritmo vegetal, Paisaje innumerable y Mazurka o en el mural El viento ordena el paisaje. El movimiento como negación de toda actitud estática, definida, permanente, lo preocupará constantemente.

Opuesta a la pintura de Vargas Rosas es la de Héctor Cáceres, pintor de clara tendencia expresionista. Si le encontrara un paralelo en el arte chileno es con el escritor González Vera. Hay en Cáceres la misma preocupación por una humanidad sórdida, un mismo amor por la sencillez y humildad de los seres y de los objetos. No hay énfasis en él, todo lo contrario, una contemplación, si bien no benévola, por lo menos tácita y dolorosa.

Israel Roa es otro de los cultores del expresionismo entre nosotros. Pero al contrario de Cáceres, tiene una paleta más exaltada. Mientras el primero es el pintor del dolor ensordecido, Roa es de humor más variado.

En las proximidades del año 30 se formó el grupo Mandrágora. Indudablemente tuvo' mayor trascendencia literałtia. Capitaneados desde afuera por Vicente Huidobro, al grupo pertenecieron Teófilo Cid, Braulio Arenas, Pilo Yáñez, Eduardo Anguita, Haroldo Donoso, etc. Pertenecen al surrealismo en Chile otros pintores, que nada tienen que ver con el grupo Mandrágora. Son ellos Francisco Morel Riesco y Susana Mardones.

En la década del 40, la guerra mundial hace recogerse a los chilenos en casa, o mejor dicho, volver al país. Coinciden esos años con la creación de varias instituciones de orden cultural: el Teatro Experimental, el Instituto de Extensión Musical, la Escuela de Dan$z a$, etc.

La joven generación de pintores participa en todos estos movimientos. ¿Cómo? Podríamos decir que compartiendo las actividades. Las salas de exposición se han ido multiplicando. Durante el invierno, semana a semana, los pintores muestran sus trabajos a un público de todas las edades. 
Existen algunos grupos de pintores. Por ejemplo, el formado por los de la Escuela de Bellas Artes, otro por algunos alumnos de la Facultad de Arquitectura de la Universidad Católica, y otro completamente independiente. Pertenecen al grupo de la Católica: Nemesio Antúnez, Pablo Burchard (hijo), Ernesto Barreda, Raimundo Infante, Exequiel Fontecilla, etc. Podemos asociar a este grupo a dos pintores que gozan de gran fama en Estados Unidos y Europa. Me refiero a Roberto Matta y Enrique Zañartu.

En el grupo de la Escuela de Bellas Artes, se destaca, en primer lugar, Gregorio de la Fuente, el más joven de los mayores y el más viejo de los jóvenes. Pintor de caballete, pero también muralista, comparte el abstraccionismo de Europa y ciertas tendencias de una pintura social, familiar a los muralistas mexicanos. Sin embargo, lo que destaca en de la Fuente no es ese espíritu combativo de los pintores mexicanos, sino una ternura especial por el hombre, eterno problema del universo. Si en su tela Hambre en la ventana hay una indudable inclinación social y un desesperado dramatismo, Hermanos es, en cambio, la tela que mejor refleja el espíritu tierno de este pintor.

La manera europeizante en la pintura chilena, se vió contrarrestada por otra de índole muy diferente, llegada al país hacia 1941. Me refiero a la influencia del muralismo social mexicano. Un acontecimiento dramático muy lejano a la pintura nos trajo la visita de David Alfaro Siqueiros y Javier Guerrero. En 1939 se produjo el terremoto de Chillán. Luego del sismo el gobierno mexicano donó a la destruída ciudad una escuela. Y para decorarla llegaron dos destacados muralistas aztecas. David Alfaro Siqueiros, con su temperamento inflamable, supo despertar simpatías entre los pintores chilenos, especialmente entre algunos jóvenes. Es así como impresionó a Venturelli, uno de los talentos más sólidos y destacados de la joven generación. Venturelli trató de hacer una pintura chilena o americanista, pero la influencia mexicana - por aquel entonces- era notoria. Actualmente Venturelli parece haber encontrado una veta puramente pictórica, más alejada de ideales políticos, y esperamos de 
él obras tan buenas como las que realizó durante su viaje por China.

En el grupo de los independientes, debemos incluir un buen número de pintores que trabajan seriamente y son de gran interés. Juana Lecaros es una de las pocas representantes de la pintura ingenua entre nosotros. Sólo podríamos recordar a Herrera Guevara como su antecesor. Lucía López busca una expresión violenta y la cristalización hacia una muestra autóctona. Byron Gigoux, solitario, por sus propios medios supo mirar al mundo de Chile hacia el mar, sin caer en el cuadro de marina tan convencional. El gran mérito de Gigoux es haberse descubierto a sí mismo por la senda del color y de la imaginación. Hermanssen se destaca dentro del campo de una pintura puramente abstracta, con dejos de una atmósfefra sin límites y sin frenos. Víctor Carvacho se mantiene también dentro del campo de la abstracción pura. Alfonso Luco parece buscar el campo de acción de los muralistas del siglo XII, dentro de una pintura figurativa y esquemática. Pablo Burchard (hijo) añora los grandes espacios en donde el sol juega de alguna manera con la penumbra. Pero también ha sabido captar últimamente un ambiente netamente santiaguino en sus telas, representando calles y barrios con indudable sabor local.

Antes de terminar esta charla, quisiera añadir unas palabras acerca de Enrique Zañartu, quien después de varios años de ausencia nos ha presentado una excelente exposición. Hablar de la pintura de Zañartu es hablar del mundo de Zañartu.

Todos los grandes maestros tuvieron su mundo propio, su cosmos. El hombre que nos presentó el Greco no fué un alucinado - como pretende Marañón-, pero sí hacinado por sus problemas religiosos. Rembrandt nos mostró al hombre en la sombra pugnando por alcanzar la luz. Para Goya el hombre no fué más que un pelele - por el cual ocasionalmente se podía sentir piedad-; para Picasso, el hombre fué una forma desorganizada en un mundo mecanizado y por lo tanto un mundo inhumano. Zañartu vuelve a la naturaleza, encarna al hombre en su deambular por la tierra en un ambiente frío e inhóspito en el cual -realmente- el hombre es siempre un in- 
adaptado. ¡Esas piernas largas de un errante sin tregua, esa angustia de caminar en un mundo adverso y helado por lo tanto, caminar sin paz y sin fin... hacia un fin sin límites!

Hablar de Zañartu, no es necesario hablar de formas o de colores. Es todo esto y mucho más y por eso creo que es suficiente con lo dicho.

Señoras y señores, ahora que hemos recorrido un buen trozo de pintura chilena, perdonad todos aquellos nombres que debieran haberse mencionado y no lo hicimos. El tiempo apremia. Pero antes de despedirnos, echemos una mirada retrospectiva hacia nuestra cordillera, hacia nuestros campos y nuestros valles. Frente a la gran mole de la cordillera, frente a ese drama en potencia, frente a la eterna contemplación de la naturaleza, el hombre de Chile vive y vibra con la inquietud del momento, verdadero sentido de un pueblo que ama el arte sobre manera y sabe crearlo. Visto lo cual parece ya imposible negar el arte nacional. Sólo nos queda cerrar esta charla con la frase del salmo que dice: - "Bienaventurado el pueblo que tiene esto..." 